\title{
Effect of hydroxychloroquine on COVID-19 prevention in cancer patients undergoing treatment: a structured summary of a study protocol for a randomised controlled trial
}

Abolghasem Allahyari ${ }^{1}$, Hossein Rahimi ${ }^{1}$, Majid Khadem-Rezaiyan², Zahra Mozaheb ${ }^{1}$, Mohsen Seddigh-Shamsi ${ }^{3}$, Alireza Bary', Mostafa Kamandi', Sajad Ataei Azimi', Saeed Eslami HasanAbadi', Alireza Noferesti', Somayeh Sadat Shariatmaghani ${ }^{1} \mathbb{D}$, Houshang Rafatpanah ${ }^{5}$ (D) Shohreh Khatami ${ }^{6}$, Afshin Jabbar Imani ${ }^{1}$, Hassan Mortazi ${ }^{1}$ and Mohammad Moeini Nodeh ${ }^{1,7^{*}}$ (D)

\begin{abstract}
Objectives: In this study, we investigate the effect of hydroxychloroquine on the prevention of Novel Coronavirus Disease (COVID-19) in cancer patients being treated.

Trial design: This is a multi-centre, two-arm, parallel-group, triple-blind, phase 2-3 randomised controlled trial. Participants: All patients over the age of 15 from 5 types of cancer are included in the study. Patients with acute lymphoid and myeloid leukemias in the first line treated with curative intent, patients with high-grade nonHodgkin's lymphoma treated with leukemia protocols and patients with non-metastatic breast and colon cancer in the first line of treatment will enter the study. The exclusion criteria will include known sensitivity to Hydroxychloroquine, weight below 35 kilograms, history of retinopathy, history of any cardiac disease, acute respiratory tract infection in the last 2 months, having COVID-19 in the first two weeks of entering the trial, having Diabetes Mellitus, having an immuno-suppressive disease other than cancer, having chronic pulmonary disease and taking immunosuppressant drug other than chemotherapeutic agents for current cancer. This study is performed in five academic centres affiliated to Mashhad University of Medical Sciences, Mashhad, Iran.
\end{abstract}

(Continued on next page)

\footnotetext{
* Correspondence: moeininm@mums.ac.ir

'Division of Hematology and Oncology, Department of Internal Medicine, Faculty of Medicine, Mashhad University of Medical Sciences, Mashhad, Iran ${ }^{7}$ Hematology and Oncology Section, Internal Medicine Department, Ghaem Hospital, Ahmadabad Ave, Shariati Sq, Mashhad, Iran

Full list of author information is available at the end of the article
}

C C The Author(s). 2020 Open Access This article is licensed under a Creative Commons Attribution 4.0 International License, which permits use, sharing, adaptation, distribution and reproduction in any medium or format, as long as you give appropriate credit to the original author(s) and the source, provide a link to the Creative Commons licence, and indicate if changes were made. The images or other third party material in this article are included in the article's Creative Commons licence, unless indicated otherwise in a credit line to the material. If material is not included in the article's Creative Commons licence and your intended use is not permitted by statutory regulation or exceeds the permitted use, you will need to obtain permission directly from the copyright holder. To view a copy of this licence, visit http://creativecommons.org/licenses/by/4.0/. The Creative Commons Public Domain Dedication waiver (http://creativecommons.org/publicdomain/zero/1.0/) applies to the data made available in this article, unless otherwise stated in a credit line to the data. 


\section{(Continued from previous page)}

Intervention and comparator: Patients are randomly assigned to two groups; one being given hydroxychloroquine and the other is given placebo. During two months of treatment, the two groups are treated with either hydroxychloroquine (Amin ${ }^{\otimes}$ Pharmaceutical Company, Isfahan, Iran) or placebo (identical in terms of shape, colour, smell) as a single $200 \mathrm{mg}$ tablet every other day. Patients will be monitored for COVID-19 symptoms during the follow-up period. If signs or symptoms occur (fever, cough, shortness of breath), they will be examined and investigated with a high-resolution computed tomography (CT) scan of the lungs, COVID-19 specific $\operatorname{lgM}$, lgG antibody assay and a nucleic acid amplification test (NAT) for the SARS-CoV-2 virus.

Main outcomes: The primary end point of this study is to investigate the incidence of COVID-19 in patients being treated for their cancer over a 2-month period.

Randomisation: Randomisation will be performed using randomly permuted blocks. By using an online website (www.randomization.com) the randomization sequence will be produced by quadruple blocks. The allocation ratio in intervention and control groups is 1:1.

Blinding (masking): Participants and caregivers do not know whether the patient is in the intervention or the control group. The outcome assessor and the data analyst are also blinded to group assignment.

Numbers to be randomised (sample size): The calculated total sample size is 60 patients, with 30 patients in each group.

Trial Status: The trial began on April 14, 2020 and recruitment is ongoing. Recruitment is anticipated to be completed by June 14, 2020 There has been no change in study protocol since approval, protocol version 1 was approved April 12, 2020.

Trial registration: This trial has been registered by the title of "Effect of Hydroxychloroquine on Novel Coronavirus Disease (COVID-19) prevention in cancer patients under treatment" in Iranian Registry of Clinical Trials (IRCT) with code "IRCT20200405046958N1", https://www.irct.ir/trial/46946. Registration date is April 14, 2020.

Full protocol: The full protocol is attached as an additional file, accessible from the Trials website (Additional file 1). In the interest in expediting dissemination of this material, the familiar formatting has been eliminated; this Letter serves as a summary of the key elements of the full protocol.

Keywords: COVID-19, Randomised controlled trial, Protocol, Hydroxychloroquine, Acute Lymphoid Leukemia, Acute Myeloid Leukemia, Breast cancer, Colon cancer, Prophylaxis

\section{Supplementary information}

Supplementary information accompanies this paper at https://doi.org/10 1186/s13063-020-04485-x.

\section{Additional file 1.}

\section{Acknowledgements}

We thank the Vice Chancellor for Research of Mashhad University of Medical Sciences for supporting this project. Also, the help of Clinical Research Development Unit of Akbar Hospital (affiliated to Mashhad University of Medical Sciences, Mashhad, Iran) in designing the study and methodological issues is highly appreciated.

\section{Authors' contributions}

Study design: MMN, AA, MKR, AB, SAA, MK, ZM, MSS, SE. Data gathering: MMN, AA, HR, SSS, AN, HR, SK, AJl, HM. Statistical Analysis: MKR, MMN, SE. Drafting the manuscript: MMN, AA, MKR, HR, AB, SAA, MK, ZM, MSS, HR. Final approval: All authors will approve the final version of manuscript and take direct responsibility for it.

\section{Funding}

All the financial resources required for this project have been provided by the Vice-Chancellor for Research of Mashhad University of Medical Sciences (code:990046). The funding body has no role in the design of this study, collection, analysis, and interpretation of data and in writing the manuscript.

\section{Availability of data and materials}

The final dataset of the trial will be available upon request from the primary investigator via e-mail at moeininm@mums.ac.ir, after obtaining the permission of the Regional Ethics Committee.

\section{Ethics approval and consent to participate}

The trial has been approved by the Ethical Committee of Mashhad University of Medical Sciences, Iran. Ethics committee reference number is IR.MUMS.REC.1399.078 which was registered on April 12, 2020. (Publicly available at this link)

Hereby we certify that this trial has received ethical approval from the aforementioned ethical committee as described above.

An informed consent is obtained from all participants or their legal guardians prior to recruitment.

\section{Consent for publication}

Not applicable.

\section{Competing interests}

The authors declare that they have no competing interests.

\section{Author details}

${ }^{1}$ Division of Hematology and Oncology, Department of Internal Medicine, Faculty of Medicine, Mashhad University of Medical Sciences, Mashhad, Iran.

${ }^{2}$ Community Medicine, Clinical Research Development Unit, Faculty of Medicine, Mashhad University of Medical Sciences, Mashhad, Iran.

${ }^{3}$ Department of Internal Medicine, Faculty of Medicine, Mashhad University of Medical Sciences, Mashhad, Iran. ${ }^{4}$ Medical Informatics, Pharmacy School, Mashhad University of Medical Sciences, Mashhad, Iran. ${ }^{5}$ Immunology, 
Immunology Department, Faculty of Medicine, Mashhad University of Medical Sciences, Mashhad, Iran. ${ }^{6}$ Internal Medicine, Department of Internal Medicine, Faculty of Medicine, Mashhad University of Medical Sciences, Mashhad, Iran. ${ }^{7}$ Hematology and Oncology Section, Internal Medicine

Department, Ghaem Hospital, Ahmadabad Ave, Shariati Sq, Mashhad, Iran.

Received: 30 May 2020 Accepted: 6 June 2020

Published online: 26 June 2020

\section{Publisher's Note}

Springer Nature remains neutral with regard to jurisdictional claims in published maps and institutional affiliations.

Ready to submit your research? Choose BMC and benefit from:

- fast, convenient online submission

- thorough peer review by experienced researchers in your field

- rapid publication on acceptance

- support for research data, including large and complex data types

- gold Open Access which fosters wider collaboration and increased citations

- maximum visibility for your research: over $100 \mathrm{M}$ website views per year

At BMC, research is always in progress.

Learn more biomedcentral.com/submissions 